\title{
Alterstice
}

Revue internationale de la recherche interculturelle

International Journal of Intercultural Research

Revista International de la Investigacion Intercultural

\section{Conte et inter-cultures au Québec : vers une pratique collaborative d'un lien de mémoire}

\section{Myriame Martineau}

Volume 5, numéro 2, 2015

Patrimoine et interculturalité

URI : https://id.erudit.org/iderudit/1036693ar

DOI : https://doi.org/10.7202/1036693ar

Aller au sommaire du numéro

Éditeur(s)

Alterstice

ISSN

1923-919X (numérique)

Découvrir la revue

Citer cet article

Martineau, M. (2015). Conte et inter-cultures au Québec : vers une pratique collaborative d'un lien de mémoire. Alterstice, 5(2), 79-88.

https://doi.org/10.7202/1036693ar

\section{Résumé de l'article}

Cet article se penche sur la pertinence d'utiliser les contes comme sources orales patrimoniales dans notre compréhension du monde actuel et propose quelques pistes de réflexion, à partir de la pratique sociale et artistique des conteuses et conteurs québécois. L’auteure se penche sur la problématique du conte contemporain québécois, à la fois comme lien de mémoire pour appréhender certains aspects de l'histoire et du patrimoine commun d'une société, comme récit de l'expérience humaine et comme véhicule de l'identitaire. Tout en remettant en question le concept d'interculturalité et lui préférant celui d'inter-cultures, cet article examine une pratique exploratoire de «l'objet-conte » auprès de personnes issues de l'immigration et en apprentissage du français au Québec, afin de saisir comment il est possible de partager des mémoires contenues dans les contes et de mettre en dialogue les fragments de cultures auxquels ils font référence. 
ARTICLE THÉMATIQUE

\section{Conte et inter-cultures au Québec : vers une pratique collaborative d'un lien de mémoire}

Myriame Martineau $^{1}$

\section{Résumé}

Cet article se penche sur la pertinence d'utiliser les contes comme sources orales patrimoniales dans notre compréhension du monde actuel et propose quelques pistes de réflexion, à partir de la pratique sociale et artistique des conteuses et conteurs québécois. L'auteure se penche sur la problématique du conte contemporain québécois, à la fois comme lien de mémoire pour appréhender certains aspects de l'histoire et du patrimoine commun d'une société, comme récit de l'expérience humaine et comme véhicule de l'identitaire. Tout en remettant en question le concept d'interculturalité et lui préférant celui d'inter-cultures, cet article examine une pratique exploratoire de "l'objet-conte " auprès de personnes issues de l'immigration et en apprentissage du français au Québec, afin de saisir comment il est possible de partager des mémoires contenues dans les contes et de mettre en dialogue les fragments de cultures auxquels ils font référence.

\section{Rattachement de l'auteure}

${ }^{1}$ Université du Québec à Montréal, Québec, Canada.

\section{Correspondance}

martineau.myriame@uqam.ca

\section{Mots clés}

conte, oralité, mémoire, identité, inter-cultures, conteurs et conteuses.

\section{Pour citer cet article}

Martineau, M. (2015). Conte et inter-cultures au Québec : vers une pratique collaborative d'un lien de mémoire. Alterstice, 5(2), 79-88. 


\section{Introduction}

Il était une fois... Ainsi commencent toutes les histoires qui n'ont jamais eu lieu. Les mythes, les fables, les légendes. [...] /I était une fois... : corpus d'une mémoire plus profonde et aigüe que celle de l'Histoire; semence du réel qui au matin oublie cet ensemencement pour n'en retenir que les traces visibles, palpables. (Germain, 2007, p. 250-251)

C'est ce rapport complexe entre une histoire individuelle (ici, le personnage du roman a perdu une partie de sa mémoire), les contes comme patrimoine immatériel de l'humanité selon l'UNESCO en 2001 et ce qui peut correspondre à un enjeu mémoriel de société que j'aimerais explorer dans cet article. Si l'oralité du conte refait surface depuis une vingtaine d'années avec ce qu'on appelle le Renouveau du conte (Martineau, 2016a; Massie, 2001), les contes performés par les conteuses et les conteurs au Québec peuvent-ils servir de dialogue interculturel entre les personnes issues de l'immigration et la société d'accueil?

Afin de saisir la diversité des rapports entre les contes qui circulent dans notre société, qu'on peut considérer comme " des objets optimaux pour la mémoire humaine » (Sperber, 1996, p. 103), et certains moments historiques au Québec, appartenant à un patrimoine commun, j'examinerai dans un premier temps en quoi et comment les contes peuvent être des sources orales privilégiées dans notre appréhension du monde et surtout dans notre rapport à l'Autre, dans le sens où les contes sont une pratique sociale,

une pratique d'actions et de représentations qui a ses motifs, ses causes et ses règles, insérés dans un contexte de reformulation et de résistance à la discipline et à la vigilance. Dans les actions et représentations de la culture populaire, le silence, l'implicite, l'invisible, sont souvent plus importants que le manifeste lui-même. (Patrini, 2009, p. 70)

Quel type de connaissances les contes véhiculent-ils? Peuvent-ils participer d'une mémoire partiellement partagée qui se construit à partir de "tris, ajouts, éliminations dans les héritages » et qui suppose une "écoute partagée " à l'intérieur d'un groupe restreint, "où les mémoires individuelles veulent et peuvent s'ouvrir les unes aux autres » (Candau, 2005, p. 80-81)? Sont-ils seulement des récits initiatiques pour reconstruire notre passé, c'est-à-dire ce que nous retenons ou oublions de l'Histoire, ou, plus encore, un type d'expérience questionnant les dynamiques interculturelles de la société? II semblerait que les conteuses et conteurs contemporains au Québec, par leur pratique d'une nouvelle "oralité performée " des contes (Martineau, 2016a), contribuent à tisser des liens identitaires entre les acteurs sociaux et à les renforcer, en ressuscitant des histoires dites traditionnelles, en se les appropriant d'une nouvelle façon, en ré-évoquant la mémoire et en revisitant un passé commun de la société dans laquelle nous évoluons. C'est ce que j'exposerai à partir d'une analyse de quelques contes issus des répertoires de Jocelyn Bérubé, Joujou Turenne, Claudette L’heureux et Petronella van Dijk.

Dans un second temps, je partirai de ma propre praxéologie du conte au Québec et au Canada ${ }^{1}$ pour souligner la parole-puissance (Durand, 1992) du conte qui sert, à mon avis, de vecteur pour un dialogue fructueux entre les cultures. Je m'inspirerai d'une trentaine d'ateliers réalisés auprès d'adultes en francisation au Québec, portant sur la description d'un objet représentatif de la culture de leur pays d'origine et important pour eux, afin de mettre en lumière le pouvoir intégrateur des contes dans la production de mémoires partagées. Car, bien que stéréotypé dans sa forme et universel dans son déploiement, le conte possède une valeur intrinsèque de définition de l'altérité et de notre rapport à l'Autre.

\section{Le conte comme lieu de partage de mémoire}

Les contes aujourd'hui permettent « une prise de conscience des individus de leur caractère propre et les aident à intégrer la communauté »(Hernandez, 2006, p. 39). Les histoires performées par les conteurs dans notre espace public ne sont pas de simples «traces » de l’Histoire. Elles se rapportent à la mémoire partagée, qui paraît « plus

\footnotetext{
${ }^{1}$ Conteuse et écrivaine, sous mon nom d'artiste Myriame El Yamani, j'ai aussi été directrice artistique de deux organismes voués à la promotion du conte : la NICA (Nuit internationale du conte en Acadie), festival international de conte de 2002 à 2006, et la Maison internationale du conte à Montréal de 2006 à 2012. J'ai offert plus d'une centaine d'ateliers d'initiation au conte et à la prise de parole en public pour toutes sortes de public (adultes en apprentissage du français, enseignant s, conteuses et conteurs de la relève, etc.) et près de 1000 ateliers pour les jeunes, au Canada, aux États-Unis, en Europe et en Afrique.
} 
opératoire que la mémoire collective, en ce sens qu'elle suggère l'existence de processus concrets de convergence, de rencontre et d'agrégation de souvenirs, rendus possibles par la présence des sociotransmetteurs " (Candau, 2005, p. 77). Elles représentent cette parole en liberté que le conte peut offrir à l'humanité et permettent de tisser un nouveau lien social entre les individus d'une société. Mon approche sociologique de l'oralité à travers les contes (Martineau, 2016b) ne se situe donc pas au niveau de la parole des "Anciens ", largement étudiée par les anthropologues et folkloristes. Elle tente plutôt de saisir la pertinence de la voix des conteuses et conteurs contemporains dans les rapports entre mémoire et Histoire, là où le conte, agissant comme référence patrimoniale, permet de donner sens aux récits oraux de notre société. Avons-nous encore " cette capacité d'échanger des expériences » (Benjamin, 2011, p. 54), d’agir avec une voix singulière et plurielle sur notre société, plutôt que de la décrire, et ainsi de participer à l'histoire en train de se faire? Les conteuses et conteurs contemporains au Québec ne se réfèrent plus à une tradition orale de transmission de contes, leur pratique de l'oralité se basant presque exclusivement sur des récits écrits. La question qui se pose est de savoir comment analyser l'oralité des contes, en tenant compte à la fois du contenu, de la " performance » des conteurs et de la réception du conte, puisque ces trois éléments font partie intégrante d'une même source d'interprétation et dont l'historicité n'est pas vraiment contestée par les auditeurs-participants. Prenons l’exemple de Rocket, un conte de Jocelyn Bérubé (2003).

Rocket n'est pas seulement un personnage issu de l'imaginaire du conteur. Il fait partie de notre histoire, peut-être pas de l'histoire officielle des livres d'école, mais d'une autre histoire, celle des "petites gences " comme dirait l'écrivain Yves Thériault, souvent oubliée, parfois reniée. Jocelyn Bérubé nous raconte les « émeutes du Forum de Montréal »le 15 mars 1955 contre le président de la Ligue nationale de hockey, Clarence Campbell, en mêlant un porteur de pancartes, Jean-Jean à Johnny, les exploits du célèbre hockeyeur canadien-français Maurice Richard et un géant d'un vieux conte anglais (Jack and the bean). II ne nous fait pas seulement participer " en direct " à une partie de hockey, avec son violon en forme de batte, il nous offre aussi une critique sociale de l'époque, où cette émeute avait en quelque sorte amorcé la Révolution tranquille, remis en question le pouvoir du clergé et les rapports de pouvoir entre Canadiens-anglais et Canadiens-français. Le conteur reprend ainsi dans son conte un extrait du sermon de l'archevêché entendu à la radio CKAC, où le prêtre fustige le hockey « [qui] se dresse en religion profane. [...] Espérons, mes chers frères, que sa récente suspension [celle de Maurice Richard] de la Ligue nationale ne sera pas une graine fomenteuse de subversion! » (Bérubé, p. 26). Il s'amuse à nous décrire la partie de hockey, où Rocket compte des buts pour aller chercher le soleil qu'on a dérobé aux ... Canadiens-français, dans cette période de " grande noirceur », comme certains historiens l'ont qualifiée.

Rocket de Jocelyn Bérubé devient matière vivante, source orale pour saisir les enjeux sociopolitiques et les conditions de vie des Canadiens-français de cette époque. Le texte du conte, poétique de surcroît, est essentiel pour comprendre l'ampleur de cet événement dans I'histoire du Québec, mais il n'est pas suffisant. II nous manque la mise en bouche, la mise en espace, en fait le « racontage » du conte par le conteur lui-même ainsi que la mise en relation avec l'auditoire qui écoute le conte. Comme le souligne Pons (2005) :

Ce que nous croyons distinct, pour le conteur, serait la qualité directe de cette relation entre lui et les gens venus l'écouter, d'humain à humain; la relation serait la finalité, le conte en serait le lien, l'objet de partage. La relation du conteur contant à ceux qui l'écoutent se veut ainsi essentielle, première, fondamentale à l'acte de conter. (p. 4)

La mise en contexte historique du conte est toujours significative, mais c'est la présence du conteur dans l'ici et maintenant qui est remarquable. Il ne nous initie pas seulement au hockey, il nous transporte aussi dans son univers fantastique, en stimulant nos sens, en nous faisant vivre cette expérience de vie, en reconstruisant le passé de ces gens qui ont marqué une époque, en nous permettant de prendre ancrage dans l'Autre avant de revenir à nous-mêmes. Ici, le conte devient art de l'expérience, production de mémoires partagées, construction d'une identité avec les liens qui nous unissent aux autres et le rapport de réciprocité qui s'établit, en performance, entre l'interprète (le conteur), le récit (le raconté) et l'auditeur (l'assistant).

Ce va-et-vient dans l'instant présent, entre ce qui est conté et ce qui fait référence à l'Histoire, entrerait dans une approche de l'inter-cultures (Emongo et White, 2014), où la rencontre entre personnes venant d'horizons et de référents culturels différents est stimulée par les contes et les récits partagés. Cette notion d'inter-cultures renvoie à l'idée d'un échange, d'une conversation, où "la rencontre des cultures est multidimensionnelle (dimension virtuelle, physique et authentique) " (p. 234-235) et où celles-ci s'interpellent continuellement. La question qui se 
pose alors est de savoir en quoi le conte permet justement cette interpellation entre les fragments de culture ainsi exposés.

\section{Comment inventer une parole de dialogue avec l'Autre, une parole conteuse qui fait sens?}

Le renouveau du conte au Québec qu'on peut situer autour des années 1990 et, qui correspond à l'époque des soirées des Dimanches du conte au Sergent recruteur à Montréal ${ }^{2}$, permet de saisir les contours, certes flous et incertains, d'une parole conteuse au Québec et de tenter ainsi de nommer un ensemble mémoriel cohérent dans notre conscience collective. Actuellement, une centaine de conteurs sont inscrits au bottin des conteurs du Regroupement du conte au Québec ${ }^{3}$, dont une majorité de conteuses depuis peu $(54,45 \%$ en 2014). Alors que racontent ces passeurs/ses d'histoires, ces tricoteurs/ses de mémoire, ces faiseurs/ses d'identité pour qu'on puisse utiliser leurs contes dans l'histoire et les représentations sociales d'un Québec « interculturel "? La thématique des contes au Québec est, comme ailleurs dans le monde, infinie, même si parfois elle fait référence à des moments historiques précis. Mais, le plus souvent, les contes contemporains remettent au goût du jour des personnages oubliés, méconnus ou ignorés de notre histoire.

Joujou Turenne, par exemple, se présente sur son site web (http://www.joujouturenne.com/accueil.php) comme « une descendante de la reine Sarraounia, de la princesse Yenenga, de la reine Aminata, l'arrière-petite-fille d'Anacaona, reine de Quisqueya. Quisqueya, l'autre nom d'Haïti. Avant l'arrivée de Christophe le colon. Toutes ces reines et princesses d'Afrique et de la Caraïbe ont combattu pour la liberté, la dignité, l'amitié. Je suis héritière d’Harriet Tubman, de Claudia Jones. Je suis le reflet de votre regard ».

On entre avec cette conteuse dans un autre registre de l'histoire du Québec, celle des Haïtiens et, plus généralement, des Afro-Canadiens ou Afro-Américains, ayant connu l'errance, l'exil, mais aussi l'esclavage comme en témoigne la figure emblématique de Marie-Josèphe Angélique qui vient juste d'être reconnue au Québec ${ }^{4}$.

Récemment, Joujou Turenne (2010) a utilisé son talent pour nous raconter des histoires qui parlent d'amour, d'entraide, de courage et d'espoir, en hommage aux millions d'orphelins du séisme survenu en Haïti en 2010, et faire en sorte que le tragique de cet événement puisse aussi devenir comique et drôle à travers les péripéties d'un Monsieur Haricot ou d'un « Ti zwazo ». Elle participe du sens à donner à un tel drame qui, au-delà de la vive émotion qu'il a suscité au Québec et dans le monde, la touche et permet d'engager son être entier dans la parole à donner. Car les conteuses et conteurs contemporains doivent nous faire rêver, voyager et surtout arriver à cette incandescence de vie qui fait de l'acte de raconter un acte hors de l'ordinaire.

Ici, le concept d'oralité des contes ne se réduit donc pas à l'action de la voix, celle-ci implique tout ce qui en nous s'adresse à l'Autre: un geste muet, un regard, une intonation. II s'agit, selon Zumthor (1983, p. 193), de l'art d'interpréter une parole qu'il définit comme performance, «[où...] sa transmission de bouche à oreille opère littéralement le texte, elle l'effectue ". Cet art de performer, mettant en rapport en temps réel (en direct) l'artiste et son public, exige alors des habiletés particulières chez la conteuse et le conteur, un savoir-faire (je préciserais un savoir-dire) mais surtout un savoir-être commun entre le conteur et l'auditeur. Zumthor distingue alors la tradition (dans le sens de mémoire) de la transmission (moment de la performance) et souligne la différence entre le texte (écrit) et la performance (le texte performé, transmis, mis en gestes et en paroles). Mais il ne faut pas s'y tromper. Le conte d'aujourd'hui n'est pas un retour au conte traditionnel des " conteux » qui contaient surtout dans les chantiers ou sur les bateaux de pêche au Québec.

\footnotetext{
${ }^{2}$ Ces soirées hebdomadaires de conte ont démarré en 1998 à l'initiative d'André Lemelin et de Jean-Marc Massie et continuent encore, en ayant changé plusieurs fois de bars comme lieux de représentation. Elles sont maintenant sous la direction artistique de Jean-Marc Massie.

${ }^{3}$ Le Regroupement du conte au Québec (RCQ) est un organisme à but non lucratif qui a été fondé en 2003 pour représenter les conteuses et les conteurs du Québec auprès des institutions et qui « veut organiser et coordonner une libre concertation des différents intervenants du milieu du conte au Québec, qu'ils soient conteurs ou organisateurs, amateurs ou professionnels, spectateurs ou simplement amis du conte. " Voir http://www.conte-quebec.com.

${ }^{4}$ C'est seulement en 2006 que la ville de Montréal pose une plaque commémorative en hommage à cette esclave torturée et brulée vive en 1734 à Québec pour avoir " soi-disant " provoqué l'incendie de la ville de Montréal à cette époque-là. Un parc lui a aussi été dédié en 2012.
} 
Au contraire, comme le souligne Pons (2005):

Vivant, le conte invente et s'adapte aux contraintes et atouts de la modernité à laquelle, aujourd'hui, il appartient : I'antique mémoire, dont il est héritier et légateur, doit rester vive et éviter la sclérose des folklorisations. Dès sa redécouverte, la pratique contemporaine du conte, plus urbaine que rurale, plus publique que privée, s'est rapidement retrouvée dans des circuits autres que traditionnels et plus proches des lieux institués de la culture et du spectacle (festivals, cabarets, théâtres, etc.). (p. 7)

La parole du conte au Québec est, comme ailleurs dans le monde, en constante évolution et mutation. Dès lors, un conte contemporain amène de nouvelles perspectives, de nouvelles explications ou compréhensions du monde qui nous entoure. L'auditoire (certains conteurs québécois comme Lemelin [2005] diront l'assistance) auquel s'adresse le conte est d'abord et avant tout d'aujourd'hui, dans l'ici et maintenant. À la différence du conteur traditionnel qui partait d'histoires transmises oralement dans sa communauté pour se les approprier et les raconter, le conteur contemporain s'inspire généralement de textes écrits qu'il s'approprie et réactualise pour correspondre à son environnement social, politique et culturel d'aujourd'hui. Dans le premier cas de figure (le conteur dit traditionnel), on y décèle plus un rapport à la tradition orale et à sa transmission (ici ce serait l'histoire qui serait au cœur de la pratique et le conteur serait alors un passeur d'histoires). Dans le second cas de figure (le conteur contemporain), on retrouve plus un rapport à la performance et au spectacle (ici ce serait la mise en " scène ", sorte de mise en espace et de mise en bouche de l'histoire qui serait privilégiée et le conteur serait alors un artiste, un " performeur »).

Bien sûr, les conteuses et conteurs contemporains québécois peuvent passer de l'un à l'autre de ces deux cas de figure. D'après mon expérience de conteuse et d'organisatrice d'événements de conte, on peut conclure que c'est l'oralité qui est devenue un art pour ces artisans et artistes de la parole. C'est le fait de dire, de " raconter ", de « performer » qui semble important. Or un conte, par sa structure assez rigide, ne se situe jamais dans l'absence de sens. Il peut ne pas nous plaire, ne pas nous toucher, mais dans tous les cas, il existe dans le conte une " morale " avec un message à porter. Toujours son écoute est multiple, son sens polyphonique, ses « lectures » plurielles avec plusieurs significations symboliques. Il suffit de penser, par exemple, aux 350 versions du Petit chaperon rouge dans le monde, pour être persuadé de la portée universelle du conte. Dans une version acadienne, le loup devient un ours et le Petit chaperon rouge un petit garçon, par exemple. Mais la morale reste la même que celle de Charles Perrault, et elle est d'ailleurs toujours d'actualité : « faire attention aux prédateurs sexuels ».

\section{Racines et identités : rencontres de mémoire, pour des adultes en francisation}

Prendre la parole en public aujourd'hui semble aller de soi, surtout avec l'avènement des nouvelles technologies et des nouveaux réseaux de communication. Pourtant, Couldry (2010), dans son essai, souligne que " nous sommes en train d'expérimenter une crise de la voix, à travers les domaines politiques, économiques et culturels ", et qu'il nous faut retrouver la " matérialité de la voix comme processus et comme valeur» (p. 1-2, ma traduction) pour non seulement prendre la parole, mais aussi se faire entendre dans notre société. C'est ce que propose Massie (2001), conteur québécois : « dans un monde où tout, absolument tout doit rapporter des dividendes, le conteur devient un rebelle qui fait acte de résistance [...], résistance à une modernité extrême qui n’a de cesse de tenter d'annihiler le pouvoir de la mémoire collective et de certaines traditions " (p. 15). Plus encore, le conteur d'aujourd'hui se doit de proposer à travers ses contes une autre façon de penser les rapports sociaux, en racontant, à travers sa voix, sa présence, sa gestuelle, ce qu'il est, ce qu'il fait et ce qu'il peut transformer pour un mieux-vivre ensemble. D'où l'idée de mettre en place en 2007, et ce jusqu'en 2012, des ateliers d'initiation au conte qui ont réuni environ 900 personnes.

Ces ateliers, intitulés Racines et identités : rencontres de mémoire, étaient basés sur cette appropriation de la parole, en français, et devant un public restreint (la classe). Ils faisaient partie d'une activité spéciale du programme de francisation offert aux nouveaux arrivants à Montréal et les classes, où j'intervenais comme conteuse exclusivement, étaient choisies par les enseignants des centres de francisation. J'étais donc considérée comme une personne ressource extérieure à leur apprentissage scolaire. Il était par contre stipulé en amont que chaque participant avait un niveau intermédiaire ou avancé dans l'apprentissage du français, c'est-à-dire était en mesure de s'exprimer au moins cinq minutes, oralement, sans support papier ou autre, dans sa nouvelle langue 
d'apprentissage. L'objectif principal de l'atelier était de permettre une rencontre de l'inter-cultures, à travers le conte, et ainsi d'offrir aux participants une autre manière, plus ludique, d'apprendre le français. La consigne pour les participants était de décrire un objet matériel apporté. L'objet devait être représentatif de la culture de leur pays d'origine et être important pour eux. Seules les photos et les vidéos étaient proscrites, car j'avais remarqué qu'elles inhibaient les personnes, qui passaient alors plus de temps à décrire la vidéo ou la photo qu'à expliquer pourquoi cet objet était significatif pour elles.

Le processus de l'atelier était toujours le même. Au départ, je racontais une ou deux histoires pour mettre les participants dans l'ambiance et l'expérience d'une séance de conte, où à la fois l'écoute et le partage des expériences de chacun et chacune sont essentiels à l'exercice. Ensuite, chaque personne venait en avant de la classe présenter son objet pendant cinq minutes exactement. Celles et ceux qui dépassaient le temps autorisé étaient alors arrêtés. Mais le plus souvent, les premiers participants n'arrivaient pas combler les cinq minutes de présentation et les autres participants ne devaient pas intervenir en posant des questions pour relancer la personne en train de parler. Nous attendions alors en silence que les cinq minutes s'écoulent. À la fin des présentations, je reprenais l'ensemble des histoires racontées à partir de l'objet et racontait le conte de la " besace du Persan $\nu^{5}$, qui intégrait au fur et à mesure de l'histoire, tous les objets présentés.

Sur l'ensemble des ateliers réalisés, j'ai pu remarquer que les objets présentés faisaient systématiquement référence au passé et surtout à l'enfance de l'individu. II est en effet plus facile de se souvenir d'un événement "heureux» qui appartient au monde de l'enfance, où l'imaginaire est souvent roi. De plus, ces objets n'appartenaient pas stricto sensu aux individus mais faisaient partie d'un patrimoine familial, en référence d'abord aux grands-parents, ensuite aux parents. Cela pouvait aller de la bague de fiançailles ou du livre de recettes de la grand-mère au carnet d'immigration (passeport d'entrée au pays) du grand-père arrivé par bateau à Halifax, à la robe de mariage typique d'un pays ou à la cuillère de la mère pour préparer la polenta. Les vêtements «traditionnels » de différents pays (chapeau, foulard, robe, ceinture traditionnelle, tunique, chaussures) ainsi que les bijoux (bague, collier, bracelet) étaient très fréquents.

Les objets présentés symbolisaient une spécificité de la culture du pays d'origine, notamment au niveau de la nourriture et des vêtements (djellaba, babouche, sari, foulard de soie, etc.). Rarement, mais quelquefois, ont été présentés des objets plus impersonnels, comme un drapeau, même si cet objet est hautement symbolique dans l'imaginaire collectif de ces immigrants. J'ai aussi observé qu'à chaque présentation, sans exception, l'objet servait de déclencheur pour se souvenir d'un moment, le plus souvent heureux, en famille, et ainsi pour prendre la parole. On peut dire que l'objet en soi devenait alors secondaire face à ce qui était en train de se passer. II s'agissait d'entrer en dialogue avec les autres pays et patrimoines culturels présents, de rencontrer l'Autre, sans se soucier de " bien parler » en français. Je ne me préoccupais pas de la qualité de la langue mais plutôt de la manière dont ces personnes me racontaient l'objet. Leur implication était grande, émotive (certains parfois ne pouvaient pas retenir leurs larmes, même si le souvenir n'était pas triste), mais à chaque fois ces personnes ont cherché à donner et à partager un peu de leur vécu et surtout à se dépasser dans la rencontre avec l'Autre. Comme le note Guilbert (1993) :

Tout élément signifiant de la culture l'est : 1) par sa relation humaine, voire internationale; 2) par sa valeur symbolique qui peut être perçue dans le quotidien pour autant qu'il revêt les couleurs locales et qu'elle exprime la tension entre les valeurs du groupe d'appartenance et les aspirations individuelles; 3) par la dynamique sociale à laquelle il participe en apportant à la fois une continuité et un potentiel d'adaptation aux changements. (p. 154)

II ne s'agit ici que de brèves observations liées à ma pratique de ces ateliers. Et c'est sans doute cette adaptation aux changements et cette relation humaine à l'Autre qui sont remarquables pour ces adultes en apprentissage du français. Non seulement ils ont pu être en mesure de comprendre une histoire en français (même si quelques mots, plus compliqués, ou moins familiers à leur quotidien, leur échappaient), mais ils ont pu également participer au conte en train de se fabriquer sous leurs yeux. En témoigne le fait que je reprenne à la fin de l'atelier ce conte des

\footnotetext{
${ }^{5}$ Ce conte des mille et une nuits reprend l'ensemble des titres des contes que Shéhérazade aurait raconté et décrit ce qu'un Persan et un kurde disent avoir dans leur besace pour la récupérer.
} 
mille et une nuits, en y intégrant tous les objets racontés. J'ai également retenu quelques commentaires d'enseignants qui ont souvent noté qu'à la suite des ateliers, il s'était passé quelque chose pour ces adultes, une sorte de " porte ouverte » sur certains aspects de leur propre patrimoine culturel mais aussi sur la société et cette nouvelle culture à apprivoiser.

Les participants ne sont pas devenus des conteuses et conteurs pour autant, mais ces ateliers leur ont donné confiance en eux et leur ont permis d'appréhender l'apprentissage du français d'une autre façon, moins " grammaticale » et plus "ludique », en se sentant valorisés par ces éléments de la culture de leur pays origine partagés devant les autres. Ils ont aussi compris qu'ils possèdent les mêmes contes, adaptés à des contextes différents, que les Québécois. "Leur peur de s'exprimer en public, en français, s'est estompée en prenant plaisir à partager une histoire et aussi en s'entraidant pour trouver le mot juste pour exprimer une émotion, en français ", ajoute une des enseignants. II demeure que ces ateliers sont des pistes exploratoires pour découvrir comment appréhender l'Autre, les multiples dimensions de la culture de l'Autre, et surtout témoigner de la richesse et du questionnement d'une pratique interculturelle artistique auprès d'adultes en apprentissage, non seulement du français, mais aussi de ce que Emongo appelle "l'inter-cultures » (2014, chap. 10). Cette pratique est encore nouvelle et son exploration demanderait à être systématisée.

\section{Retour aux « racines ", quête de l'authentique, partage de patrimoines}

Le nouveau conteur, dans sa posture contemporaine, est-il resté témoin de notre temps, comme quelqu'un qui sert de repère et de référence pour ceux et celles qui l'écoutent? La version personnelle des faits qu'il rapporte, la manière dont il s'approprie la parole et l'écoute réciproque qui en résulte, font en sorte que le conteur n'est pas un simple amuseur de foules, un bonimenteur ou un humoriste.

Quand, par exemple, Petronella van Dijk (2011) dans son spectacle, Le silence des lettres, nous raconte le temps des guerres, "ce temps de folie qui se transforme en violence et de violence qui se transforme en folie ", elle rend hommage à ces hommes et ces femmes qui ont vécu et vivent encore la guerre de nos jours et surtout elle redonne une voix à ceux et celles qui l'ont perdue face au trauma de la guerre. Lorsque les soldats sont revenus muets du front de la Première Guerre mondiale, par exemple, ce n'est pas seulement parce qu'ils étaient incapables de dire en mots les atrocités vécues, mais parce qu'ils ne pouvaient pas communiquer aux gens leurs expériences. Ils étaient, comme le note Benjamin (2011, p. 55), " pas plus riches, mais plus pauvres en expériences communicables ".

Plus encore que cette chute de valeur de l'expérience, décrite par Benjamin, c'est notre incapacité à prendre la parole et à raconter une histoire devant une assemblée qui écoute. Car écouter une histoire ou un conte, demande du temps, de la disponibilité d'esprit, et un désir d'échanger avec l'Autre, ce qui nous apparaît de plus en plus irréconciliable avec l'agitation moderne du $21^{\mathrm{e}}$ siècle. De même, prendre la parole en public exige un certain don de soi de la part du conteur, une envie de partager un message, une idée, une émotion, de faire en sorte, comme le remarque Benjamin que « le conseil [il dit que le conteur est de conseil] est en vérité moins une réponse à une question qu'une proposition concernant la suite de l'histoire en train de se dérouler. Pour aller chercher ce conseil, il faudrait tout d'abord pouvoir raconter l'histoire. [...] Nous ne sommes plus de conseil pour nous-mêmes ni pour les autres » (p. 60-61).

Je reste convaincue que l'art de raconter consiste moins à dire des mots et à les agencer de manière logique pour être compris, qu'à proposer des images qui font sens. La conteuse (ou le conteur) doit voir son récit, avant de l'exposer à l'auditoire. Mais elle doit aussi l'ancrer dans le quotidien de l'auditeur, parce qu'une nouvelle qui vient de loin sera, toujours selon Benjamin, moins écoutée que "l'information qui fournit un point d'appui pour saisir ce qu'il y a de plus proche » (p. 65). Plus la conteuse sera ancrée dans son environnement, sa modernité, sa culture, son histoire, c'est-à-dire sera " présente " à l'instant du racontage et de l'expérience à partager, plus elle aura, à mon avis, des chances d'être entendue et appréciée.

Il semble donc que le conte favorise une prise de conscience de l'être humain dans son entièreté, et affirme une identité individuelle, mais aussi collective. Comme le souligne Hernandez (2006) dans son essai sur le monde du conte en France, aux Pays-Bas et en Espagne, "le développement contemporain de l'invention des traditions est très généralement lu comme une réponse à un besoin de continuité réelle, dans un monde soumis à d'importants 
changements. L'absence d'héritage provoquerait un manque, compensé par les reconstructions du passé », que l'auteure considère comme «fondamentalement inauthentiques. [...] La définition des groupes par référence au passé serait alors le produit d'une instrumentalisation par les dominants de l'identité des dominés » (p. 151). Elle va même encore plus loin en affirmant que :

L'idéologie qui soutient les traditionalismes contemporains est une idéologie des racines qui résulte de différents parallèles : l'influence encore prégnante du mouvement romantique, des productions intellectuelles qui proposent face aux crises sociales la redécouverte de formes anciennes de solidarité et d'intégration, des politiques culturelles pour qui investir dans les racines ne présentent pas de risques réels, de nouveaux espaces de pouvoirs avec la régionalisation et les structures extra-communales. (p. 153-154).

Retrouvons-nous, dans le renouveau du conte au Québec, cette "idéologie des racines ", liée à la croyance d'une " nature » historique et culturelle du peuple ainsi désigné, les Québécois, où les racines sont transformées dans une perspective identitaire, mais renvoient aussi à des enjeux sociopolitiques et économiques, à des politiques de gestion de la diversité ethnoculturelle au Québec? Comme le souligne Juteau (2015), l'ethnicité est construite socialement et elle doit se concevoir dans ses frontières externes et internes.

L'examen d'une frontière (ethnique) interne souligne le lien entre culture et ethnicité tout en marquant la distance qui les sépare. La séparation établie par Barth (1969) entre culture et ethnicité a conduit à sous-estimer les phénomènes culturels dans les relations ethniques. Je pense aussi que la culture représente " une des dimensions de l'action, une potentialité utilisée par les individus pour forger leur monde, une action constructrice des rapports sociaux » (Bastenier, 2004), dont il faut tenir compte. (p. 135)

La question se pose lorsqu'on s'interroge sur le recours à la tradition pour parler des contes. De quelle tradition s'agit-il? Celle de nos grands-pères et grands-mères, qui justement ne nous ont pas raconté d'histoires, puisque les contes de transmission orale n'existent plus dans notre société contemporaine? La plupart de ces artisans de la parole racontent des contes traditionnels "écrits", donc déjà transformés, remodelés par les auteurs de cette littérature.

Lorsque René Robitaille (2012) avec son spectacle Le chant des os, nous parle de Jasmine, "cette femme sauvage, insaisissable, l'enfant amère d'un père fantôme dans le Moyen Nord québécois ", on retrouve cette même quête de l'authentique et des racines. Elle nous fait découvrir un pan de l'histoire de la Nation Cri et des rapports avec les "Blancs ", pour se rendre compte que l'histoire de cette femme la " renvoyait à ses propres tripes et déterrait ses lointains secrets ». Quand Claudette L'heureux (2009) raconte I'histoire du " cinq cennes » de son père, tenant un magasin à Maniwaki, on comprend mieux pourquoi les enfants adorent la crème glacée. Mais on découvre aussi les rapports entre les riches et les pauvres, la puissance de la religion catholique dans les villages québécois, la persévérance d'aller au bout de ses rêves et de ses envies.

On pourrait multiplier les exemples de contes portées par les Québécoises et Québécois qui, s’ils se réfèrent parfois à l'Histoire ou à un fait historique, restent des fragments d'histoires de gens à qui on a peu laissé la parole dans la société, et ces contes leur permettent d'exister, tout simplement. Il serait d'ailleurs important de recenser les motifs dans les contes contemporains québécois qui interrogent nos récits nationaux pour questionner la construction sociale de ce patrimoine mémoriel.

\section{Conclusion}

À travers cet examen du répertoire de quelques conteuses et conteurs québécois, il semblerait que l'appréhension d'une histoire orale du Québec à travers les contes peut être fructueuse pour les chercheurs en sciences sociales et humaines, dans la mesure où la parole conteuse québécoise actuelle peut se comprendre comme un interstice entre tradition et modernité, entre mémoire historique et fragments d'histoire. "L'oralité performée " pratiquée par les conteuses et conteurs québécois doit se saisir en terme de mise en relation de la séquence " conteur/conteuse - conte - auditeur/auditrice » pour saisir la mémoire partagée d'une société et son évolution historique. Il semble crucial d'analyser les contes comme des espaces de visibilité de voix et de paroles porteuses de sens dans notre société et les comprendre aussi comme outils d'inter-cultures dans un dialogue entre nouveaux arrivants et société d'accueil. 
Le conte contemporain est une pratique sociale et un art de la relation. De nos jours, il s'inscrit définitivement dans une perspective de performance-spectacle, à travers laquelle l'imaginaire, le symbolique et la quête identitaire des individus se retrouvent au premier plan. Le rapport privilégié entre le conteur et le public est propre à cette pratique artistique et rend unique chaque séance de racontage, puisque la transmission d'histoires se transforme selon le public et selon le contexte. C'est ce que Zumthor (2008) et d'autres auteurs ont souligné dans leur définition de l'oralité.

Qu'il soit contemporain ou traditionnel, le conte sert à raconter l'expérience humaine avec des " histoires remarquables ", et donc à reconquérir un terrain que les grands traumatismes du $20^{\mathrm{e}}$ siècle avaient transformé en no man's land. Les conteuses et conteurs, par la légèreté de leur parole et leur désir de partage, doivent permettre de raconter l'incommunicable mais aussi de critiquer tout aspect de la société qui leur semble injuste, car ils ont le privilège de rapporter leur expérience personnelle mais aussi celle des autres. "Son talent est de pouvoir raconter sa vie; sa dignité, de pouvoir la raconter toute entière. [...] Le conteur est la figure dans laquelle le juste se rencontre lui-même » (Benjamin, 2011, p. 106).

C'est ce que j'ai pu observer avec les ateliers Racines et identités : rencontres de mémoire, réalisés auprès d'adultes en francisation au Québec, où c'est l'histoire contenue dans un objet personnel qui importe plutôt que l'objet luimême. Peut-on alors parler de rencontres de cultures, où l'Autre est aussi privilégié que soi-même et où une sorte de dialogue et de rencontre interculturels entre ces nouveaux arrivants et la société d'accueil serait innovante? Ce projet exploratoire aura au moins eu l'avantage de signifier que ces adultes ont pu, grâce à ces ateliers, développer des compétences en communication, des habilités dans la prise de parole et dans la confiance en soi, en plus d'aplanir les obstacles à une expression linguistique satisfaisante en français. Ils leur ont permis de s'exprimer sur ce qu'ils ont vécu et aussi peut-être d'avoir l'impression d'être partie prenante de leur nouvelle société, comme agents et non plus comme un groupe indifférencié de nouveaux arrivants en processus d'apprentissage du français. Ce que le conte permet, $c^{\prime}$ est de valoriser un patrimoine mémoriel commun, encore à découvrir et à partager.

\section{Références}

Benjamin, W. (2011). Le conteur. Considérations sur l'œuvre de Nicolas Leskov. Dans Expérience et pauvreté (p. 51106). Paris : Payot/Rivages. (première édition 1936)

Bérubé, J. (2003). Portrait en blues de travail (livre-CD). Montréal : Planète rebelle.

Candau, J. (1998). Mémoire et identité. Paris : Presses universitaires de France.

Candau, J. (2005). Anthropologie de la mémoire. Paris : Armand Colin.

Couldry, N. (2010). Why Voice matters. Culture and Politics after Neoliberalism. London : Sage Publications.

Durand, G. (1992). Les structures anthropologiques de l'imaginaire. Paris : Dunod.

Emongo, L. et White, B.W. (2014). L'interculturel au Québec. Rencontres historiques et enjeux politiques. Montréal : Presses de l'Université de Montréal.

Germain, S. (2007). Magnus. Paris : Gallimard.

Guilbert, L. (1993). La tradition des contes et la culture québécoise (p. 145-149). Dans G. Bouchard et S. Courville (dir.), La construction d'une culture. Le Québec et l'Amérique française. Québec : Presses de l'Université Laval.

Hernandez, S. (2006). Le monde du conte. Contribution à une sociologie de l'oralité. Paris : L'Harmattan.

Juteau, D. (2015). L'ethnicité et ses frontières ( $2^{\mathrm{e}}$ édition revue et mise à jour). Montréal : Presses de l'Université de Montréal.

Lemelin, A. (2005). Le conte ne fait pas le conteur. Montréal. http://andrelemelin.com/conte-fait-pas-conteur/

L’heureux, C. (2009). Les contes de la poule à Madame Moreau (livre-CD). Montréal : Planète rebelle. 
Martineau, M. (2016a, sous presse). Le renouveau du conte au Québec : entre tradition renouvelée et oralité performée? A renovação do conto no Québec : entre oralidade "performada" e tradição "renovada" ? Dans G. Tierno de Siquiera et L. Liesenfeld (dir.), Narra-te cidade : pensamentos sobre a arte de contar historias hoje. Dire la ville : réflexions sur l'art de conter des histoires aujourd'hui. São Paulo, Brésil : Porto de Ideias.

Martineau, M., avec la collaboration de G. Tierno de Siquiera, S. Hernandez et A. Ponsin (2016b, sous presse). Le renouveau du conte au Québec, au Brésil et en France : analyse comparative et nouvelles perspectives pour une sociologie de l'oralité. Cahiers de recherche sociologique, 59/60.

Massie, J. M. (2001). Petit manifeste à l'usage du conteur contemporain. Le renouveau du conte au Québec. Montréal : Planète rebelle.

Patrini, M. (2009). Le nouveau conteur : oralité, performance et identité. Dans CMLO (Centre Méditerranéen de Littérature Orale), Histoire et littérature orale (p. 70-81). Alès. http://www.euroconte.org/LinkClick.aspx?fileticket=AhWYg9F6Ak\%3D\&tabid=548\& $\mathrm{mid}=2700 \&$ language $=\mathrm{fr}-\mathrm{FR}$

Pons, C. (2005). La nature du conte. Mémoire présenté au Conseil des arts et des Lettres du Québec. Montréal.

Robitaille, R. (2012). Le chant des os. Montréal. http://www.reneerobitaille.com.

Sperber, D. (1996). La contagion des idées. Paris : Odile Jacob.

Turenne, J. (2010). Contes de Joujou. Le vent de l'amitié (livre-CD). Montréal : Planète rebelle.

Van Dijk, P. (2011). Le silence des lettres. Sherbrooke. http://www.conte-quebec.com/conteurs/petronella-van-dijk.

Zumthor, P. (1983). Introduction à la poésie orale. Paris : Seuil.

Zumthor, P. (2008). Oralité. Intermédialités : histoire et théorie des arts, des lettres et des techniques / Intermediality : History and Theory of the Arts, Literature and Technologies, 12, 169-202. 